\title{
Safety Climate in Project-Based Organizations: Multi-Criteria Analysis
}

DOI: 10.7595/management.fon.2020.0026

\begin{abstract}
:
Research Question: The aim of this paper is to determine the factors influencing safety climate in different industrial sectors in project-based organizations. Motivation: Systematic research on occupational safety is not so frequent in the Republic of Serbia. The lack of research that deals with safety climate in project-based organizations exploring the attitudes of employees in different industrial sectors is evident. In the research conducted by Milijic et al. (2013) a model for measuring safety climate factors was proposed and the following step is to identify the most important safety climate issues for each industrial sector as a key to fostering better safety performance. Chen et al. (2018a) concluded that engagement at all levels of the company is essential to fostering better safety performances as well as that safety awareness is the most important factor influencing workers' safety efficiency. The authors of the present paper seek those particular factors that adequately describe safety climate in project-based organizations by examining the attitudes of workers in different industrial sectors. Idea: The main idea of this paper is to evaluate and rank safety climate in different industrial sectors and different workplaces considering the following five factors of safety climate: Safety and competence awareness, Occupational safety management commitment, Safety training and tools, Safety practices and procedures and Organizational environment. Data: Safety climate analysis was conducted on a set of data collected as a part of a survey carried out in eleven project-oriented organizations operating in different industrial sectors on the territory of Serbia. Tools: This paper proposes a multi-criteria analysis of the data collected from a national survey using the Entropy-PROMETHEE-GAIA method. Findings: A complete ranking of safety climate in project-oriented organizations based on the opinions of employees in different industrial sectors resulted in Energy as the bestranked sector. On the other hand, the worst-ranked sector is High-rise construction. The results of the complete ranking of safety climate in project-oriented organizations based on the opinions of employees at different workplaces in different industrial sectors showed that the best-ranked alternatives were manager working places. When it comes to production workers on projects, the most favorable safety climate is in energy workplaces and for non-productive workers, while the most favorable safety climate is on projects in the field of mechanical engineering. Contribution: Adopting the conclusions from the paper can, in practice, improve safety climate along with safety at work in project-based organizations.
\end{abstract}

Keywords: safety climate, project-based organization, multi-criteria analysis, Entropy-PROMETHEE-GAIA

JEL Classification: J28, J81

\section{Introduction}

In recent years, contemporary projects, as well as companies that implement them, have faced increasingly complex challenges, both technical and socio-economic. The reasons lie in the very dynamic changes that occur in the environment, and on the other hand, in the time-consuming process of realization and complexity of projects, difficulties in their realization, and a high level of uncertainty (Puska et al., 2018; Li et al., 2019). In such circumstances, from a contractor's point of view, goals such as time, cost, quality, performance and employee safety, need to be achieved. However, in practice, employee safety very often remains a marginalized area of business. In addition, involvement of numerous entities in the implementation of projects using complex techniques and technologies contributes to a high degree of safety risks as well as to a frequent occurrence of injuries at work. Therefore, the need for better employee safety performance 
at work is obvious. Numerous studies, as well as business practices, indicate that a more effective occupational safety management system is needed through safety risk management, communications enhancement, safety monitoring, and safety training (Yang et al., 2012; Sheehan et al., 2016; Zaira \& Hadikusumo, 2017; Versteeg et al., 2019). A more efficient occupational safety management system would accelerate the formation of a positive safety climate that would, in the long run, result in the reduction of workrelated injuries and ultimately lead to a more effective project implementation. Therefore, there is an ongoing need for research that aims to uncover organizational factors affecting the improvement of safety climate, both on projects as temporary structures and within project-oriented organizations themselves. This would represent a major step forward in finding solutions applicable in practice.

This paper is structured as follows. Paper section 2 provides the literature overview on safety climate in project-based organizations. In section 3 the research methodology will be explained in-depth. Section 4 presents research results and discussion. Finally, the conclusion is given in the last section.

\section{Literature Overview on Safety Climate}

Safety climate can be defined as employee perceptions in terms of values, attitudes, policies, and procedures that signal and indicate the importance of workplace safety (Zohar 1980; Probst et al., 2019). Given that safety climate has a positive effect on occupational safety and injury prevention (He et al., 2016; Kasim et al., 2019), this concept was been the focus of research by numerous authors. Their goal was to determine influential factors, both demographic and organizational (Alruqi et al., 2018; Newaz et al., 2019; Kim et al., 2019; Flatau-Harrison et al., 2020). It should be emphasized that these factors may not be uniform in different world economies due to the influence of cultural differences etc. and the focus is on the uniformity of employees' perceptions. Therefore, in order to create positive safety climate, it is necessary to reach a consensus of opinions, attitudes, understandings and finally, perception of safety among members of different professional groups involved in the project. By doing so, the basis for a satisfactory state of occupational safety has been formed, and the realization of projects, as well as functioning of entire projectoriented organizations, has been improved (Huang et al. 2012).

As it has already been said, safety of employees, as well as safety climate on projects, are characterized by certain specific features, so this is an area to which special attention should be paid. The greatest influence on the creation of positive safety climate on projects is represented by the safety system and employee awareness as well as their commitment to safety (Marin et al., 2019). Positive safety climate formed this way influences risks recognition, that is, the creation of adequate perception of risks in the workplace. Consequently, such a situation results in the reduction of injury frequency at the workplace, i.e. the improvement of occupational safety (Pandit et al., 2019). Of course, a company's management system has a decisive role in almost all segments of business. Thus, management commitment to occupational safety, i.e. safety practices, as well as commitment of co-workers, undoubtedly influence the formation of an effective occupational safety system. This connection is achieved through the creation and adoption of quality and purposeful safety training, procedures, as well as reduced work pressure, which actually highlights safety climate factors that are extremely important (Stackhouse \& Turner, 2019).

Studying safety climate, other authors likewise emphasize the importance of management commitment to occupational safety both on projects and within project-oriented companies, but they also focus their research on adequate communication (Curcuruto et al., 2018). Communication in the field of occupational safety, as well as dissemination of information (information sharing and dissemination) also represent a significant factor of safety climate and positive creation. This factor is especially emphasized in critical situations and in places and times when for certain reasons there is a departure from the established procedures for conducting business activities. After all, communication is one of the basic activities of an occupational safety system regardless of whether the concept of safety climate is discussed at all (Kasim et al., 2019).

Based on the results of numerous studies, it seems obvious that all the above mentioned factors of safety climate reduce risk levels and strengthen safety management (Curcuruto et al., 2018; Kasim et al., 2019; Stackhouse \& Turner, 2019). Hence, safety climate, that is, all its factors individually, can serve as a useful indicator of the level of safety at work, i.e. occurrences of occupational accidents. In addition, safety factors can become an analytical tool when studying deficiencies in an occupational safety system (Chen et al., 2018b; Marin et al., 2019).

At this point, industrial sectors in which safety climate is most often studied seem worth mentioning. In the work of Bamel et al. (2020) some of these industrial sectors are listed: construction industry, manufacturing, oil industry, agro-industry, transport industry, etc. (Bamel et al., 2020). When analyzing projects, that is project- 
oriented organizations, in the literature, exploration of safety climate can mainly be found on infrastructure projects (Lingard et al., 2017; Khodeir \& Nabawy, 2019), rail construction projects (Stiles et al., 2018) and construction projects (Saunders et al., 2017; Marin et al., 2019; Versteeg et al., 2019; Winge et al., 2019; Xia et al., 2020). Questions about the importance of emphasizing safety climate studies in various industrial sectors remain open. The answer can be found in the fact that safety climate very often differs even among different professional groups within one and the same project (Chen et al., 2018b; Marin et al., 2019).

Very few papers in the literature compare safety climate in different industrial sectors and even fewer in project-based organizations, which represents a considerable research gap. One of these rare papers is the work of Jiang et al., in which they presented a comparison of reliability of safety climate assessment in general as opposed to the assessment of safety climate in a specific industry (Jiang et al., 2018). This is the main incentive for this research to be conducted comparing safety climate in different industrial sectors in project-based organizations.

Few studies are currently investigating safety climate in companies on the territory of the Republic of Serbia (Milijic et al., 2014). When it comes to project environment, the number of such studies is even smaller. Therefore, the aim of this paper is a multi-criteria analysis of safety climate in project-oriented organizations in Serbia, while finding the related influential elements.

\section{Research Methodology}

\subsection{Questionnaire and data collection}

For the purpose of the present research, the methodology of a questionnaire for data collection was applied. The questionnaire was developed by the authors of this paper based on previous research related to the issues of safety climate and occupational safety in manufacturing companies (Milijic et al., 2013; Lin et al., 2008; Turnberg \& Daniell 2008; Hsu et al., 2008; Jiang et al., 2010, Saunders et al., 2017, Chen et al., 2018a). The questionnaire consists of two parts. The first part contains 8 demographic questions, while the second consists of 29 questions divided into 5 groups related to safety climate on projects. The first group of questions (GQ1), Safety and Competence Awareness, deals with the understanding of responsibilities concerning workplace safety, and how employees deal with safety issues and obey the rules. The second group of questions (GQ2), Occupational Safety Management Commitment, aims to assess how managers enforce occupational safety in relation to other business goals such as productivity or set deadlines. GQ2 depicts the way in which employees perceive the position of safety climate in the workplace. GQ3, Safety Training and Tools, is a group of questions that is used to evaluate the level of employees' competence to respond to safety risks, adequacy of their training, and availability of safety equipment at workplaces. The group of questions that describe Safety Practices and Procedures (GQ4) approaches specific measures and procedures that are applied both in organizations and during the realization of projects themselves. Immediate implementation of measures and procedures as well as the adequacy of responses to safety issues are evaluated. The last group of research questions GQ5, Organizational Environment, refers to the implementation of safety measures and procedures when work pressure is taken into account. The survey examines whether safety procedures are being neglected or less respected when faced with deadlines, norms and project goals.

An anonymous survey was conducted among employees of 11 project-oriented companies on the territory of Serbia. The selected companies carry out projects in various industrial sectors: mechanical engineering (I1), furniture industry (I2), energy (I3), high-rise construction (I4) and civil engineering (I5). The survey was conducted on a sample of 121 employees. A 5-point Likert scale was used to grade the respondents' answers, with values from 1 to 5 , where 1 represents the smallest significance (I absolutely disagree with the given statement) and 5 represents the highest significance (I absolutely agree with the given statement).

\subsection{Entropy - PROMETHEE - GAIA method}

This paper used the combined Entropy - PROMETHEE - GAIA method in order to rank alternatives.

The entropy method is often used as a tool for obtaining the weight of criteria. Entropy is a measure of difference in the amount of information that is contained in the value of criteria. It represents the strength of criteria describing alternatives, i.e. each value of the alternative for each criterion contains information that can be measured through the value of entropy. Weights obtained with Entropy are based on the information given in the decision matrix and represent measures of information quantity contained in the value of criteria (Hafezalkotob \& Hafezalkotob, 2016; Chirag et al., 2016). 
For the final ranking of alternatives, Preference Ranking Organization Method for Enrichment Evaluation (PROMETHEE) was used. The implementation of the PROMETHEE-GAIA method consists of several steps: first, defining all the elements of decision matrix (set of alternatives, set of criteria, importance of each criterion, preference functions for each criterion and criteria directions); then calculating the differences between two alternatives and preference of one alternative over another (Nikolic et al., 2009; Brans \& De Smet, 2016; Zivkovic, et al., 2017). Finally, The PROMETHEE ranking is based on determining the positive $(\Phi+)$ and negative flows (Ф-) for each of the alternatives. A positive flow of preference shows how much a particular alternative is prefered over other alternatives. If the value is greater $(\Phi+\rightarrow 1)$, the alternative is more significant than the other alternatives. A negative flow of preference indicates how much a particular alternative is preferred over other alternatives. The alternative is more significant if the flow value is lower $(\Phi-$ $\rightarrow 0)$. The complete ranking, according to the PROMETHEE II method, is based on the calculation of net flow $(\Phi)$, which represents the difference between a positive and a negative flow of preference. The alternatives that have the highest net-flow value are the best-ranked and so on until the lowest-ranked alternative (Anand and Kodali 2008; Brans and Mareschal 1994; Brans et al., 1986).

Ever since the first usage until today PROMETHEE method has undergone various improvements. One of the most useful that complements entropy to the method was the introduction of the GAIA plane that allows graphic presentation of obtained results (Mareschal \& Brans, 1988). Nowadays the PROMETHEE-GAIA is successfully used in various research fields such as ranking and selection of business activities planning (Kilic et al., 2015), education (Murat et al., 2015; Zivkovic et al., 2017; Ishizaka \& Resce, 2020), occupational safety (Milijic et al., 2014), as well as transportation (Sennaroglu \& Celebi, 2018).

In this paper, the Entropy- PROMETHEE- GAIA method based on 5 criteria was applied and the multi-criteria analysis of safety climate in project-oriented organizations in five types of industrial projects was made. Five groups of questions from the questionnaire -factors of safety climate: GQ1 - Safety and Competence Awareness, GQ2 - Occupational Safety Management Commitment, GQ3 - Safety Training and Tools, GQ4 Safety Practices and Procedures and GQ5 - Organizational Environment were chosen as the criteria. Alternatives were defined in accordance with the aforementioned division of industrial sectors: mechanical engineering (I1), furniture industry (I2), energy (I3), high-rise construction (I4) and civil engineering (I5).

In addition, for each project type, a multi-criteria analysis of safety climate was performed for three job positions (manager (WP1), production worker (WP2) and non-production worker (WP3)).

\section{Research Results and Discusion}

After collecting the input data from employee survey, assigning a preference function, calculating the weight coefficients of the criteria by the Entropy method and forming evaluation matrices using the Visual PROMETHEE software package, ranking the climate safety level was performed in five types of industrial projects. Subsequently, the same methodology was used to rank safety climate at different workplaces on projects.

\subsection{Multi-criteria analysis of safety climate in project-oriented organizations in} different industrial sectors

In this case, a multi-criteria analysis and the final ranking of safety climate level in project-oriented organizations in five different industrial sectors were performed. The baseline data for the implementation of the PROMETHEE method represent the average scores of respondents in the five industry sectors for all five groups of questions in the survey (Table 1).

Table 1: Baseline data for PROMETHEE calculation (safety climate in different industrial sectors)

\begin{tabular}{|l|l|l|l|l|l|}
\hline \multirow{2}{*}{ Alternatives } & \multicolumn{5}{l|}{ Criteria } \\
\cline { 2 - 6 } & GQ1 & GQ2 & GQ3 & GQ4 & GQ5 \\
\hline I1 & 4.25 & 3.46 & 3.70 & 3.75 & 3.14 \\
\hline I2 & 4.39 & 3.25 & 3.46 & 3.12 & 2.95 \\
\hline I3 & 4.29 & 3.64 & 3.76 & 3.74 & 2.87 \\
\hline I4 & 4.43 & 2.58 & 2.94 & 2.88 & 3.11 \\
\hline I5 & 4.10 & 3.44 & 3.49 & 3.63 & 3.12 \\
\hline
\end{tabular}


In the following, after entering the input data, specifying the most favorable function of preference for the analyzed data type, and determining the weight coefficients of the criteria, an evaluation matrix was formed (Table 2). On the basis of the evaluation matrix, the ranking of alternatives was conducted.

Table 2: Preference functions and weight coefficients of the criteria for the evaluation and ranking of safety climate in different industrial sectors

\begin{tabular}{|l|l|l|l|l|c|}
\hline Criteria & GQ1 & GQ2 & GQ3 & GQ4 & GQ5 \\
\hline $\begin{array}{l}\text { Weight } \\
\text { coefficients }\end{array}$ & 0.1997 & 0.2003 & 0.2000 & 0.2002 & 0.1997 \\
\hline $\begin{array}{l}\text { Preference } \\
\text { function }\end{array}$ & Level & Level & Level & Level & Level \\
\hline Min/Max & MAX & MAX & MAX & MAX & MIN \\
\hline
\end{tabular}

The results of the complete ranking (PROMETHEE II) of safety climate in project-oriented organizations based on the opinions of employees in different industrial sectors, as well as the flows of preferences, are shown in Table 3. Additionally, the ranking results are shown on the GAIA plane (Figure 1). The GAIA plane view is an extremely useful tool for drawing meaningful conclusions from the multi-criteria analysis.

Table 3: Results of the complete ranking of safety climate in project-oriented organizations based on the opinions of employees in different industrial sectors

\begin{tabular}{|l|l|l|l|l|}
\hline Rank & Alternatives & $\boldsymbol{\Phi}$ & $\boldsymbol{\Phi}$ - & $\boldsymbol{\Phi}$ \\
\hline 1 & $\mathrm{I} 3$ & 0.3252 & 0.0000 & 0.3252 \\
\hline 2 & $\mathrm{I}$ & 0.2252 & 0.0750 & 0.1502 \\
\hline 3 & 15 & 0.1502 & 0.1749 & -0.0247 \\
\hline 4 & $\mathrm{I}$ & 0.1749 & 0.2002 & -0.0253 \\
\hline 5 & 14 & 0.0250 & 0.4504 & -0.4254 \\
\hline
\end{tabular}

Based on the obtained results, it is noted that the best-ranked alternative is I3 (Energy). This means that, based on the responses of the surveyed employees, safety climate on projects in the energy was rated very favorably, which is a significant prerequisite for a high level of occupational safety. On the other hand, according to the respondents, the worst-ranked alternative is 14 (High-rise construction). It can be concluded that safety climate in the energy (I3) and mechanical engineering (I1) projects is at a satisfactory level. When looking at projects in the field of civil engineering (I5) and furniture industry (I2), there is the need for improvement of safety climate.

The decision stick (pi stick) on the GAIA plane (Figure 1) represents the weights of the criteria and indicates their reliability. Because the weights of the criteria are determined by the objective method of entropy, the GAIA plane shows a high compliance of the weight with the preferences obtained based on the respondents' answers. When it comes to the criteria, the GAIA plane indicates that there are no conflicts between safety climate factors. The distance of criteria from the coordinate start of the GAIA plane indicates that Organizational Environment (GQ5) has the highest discriminatory value in the ranking, which means that this factor has the greatest impact on the overall ranking while the factor Safety and Competence Awareness (GQ1) has the lowest value. Also, the GAIA plane indicates that in civil engineering projects (I5), safety climate factors that need to be promoted are safety awareness and competency (GQ1), training and safety tools (GQ3), and organizational environment (GQ5). When considering the opportunities for improving safety climate on projects in the furniture industry, the following factors should be emphasized: commitment to occupational safety management (GQ2), training and safety tools (GQ3), and safety practices and procedures (GQ4). Finally, for high-rise construction projects, in addition to the developed safety awareness and adequate competencies of employees, all other factors of safety climate need significant improvement. 


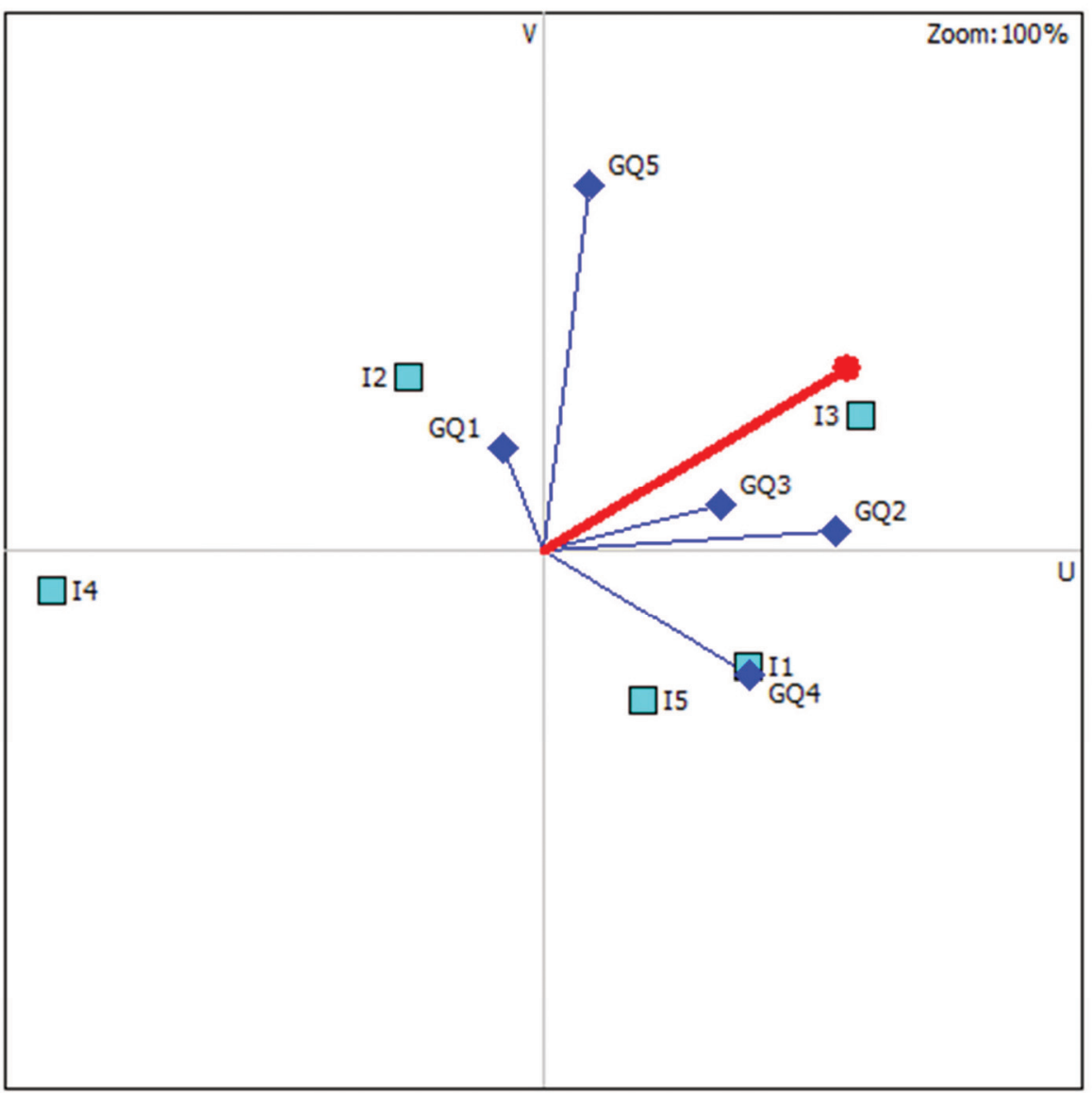

Figure 1: GAIA plane of safety climate ranking in different industrial sectors

In order to determine the magnitude of preferred relationships with a given safety climate ranking in different industrial sectors in project-oriented organizations, a sensitivity analysis of the criteria weights was performed (Table 4). With this analysis it is possible to determine the stability intervals for each criterion. The stability interval defines the limits within the range of weight coefficients of a given criterion that can be changed without affecting the resulting ranking. For that purpose, the weight of only one criterion changes, while the relative weights of the remaining criteria remain unchanged (Nikolic et al., 2009).

Table 4: Weight coefficient stability intervals

\begin{tabular}{|l|l|l|l|l|}
\hline Rank & Alternatives & $\boldsymbol{\Phi}$ & $\boldsymbol{\Phi}$ - & $\boldsymbol{\Phi}$ \\
\hline 1 & $\mathrm{I} 3$ & 0.3252 & 0.0000 & 0.3252 \\
\hline 2 & $\mathrm{I} 1$ & 0.2252 & 0.0750 & 0.1502 \\
\hline 3 & $\mathrm{I} 5$ & 0.1502 & 0.1749 & -0.0247 \\
\hline 4 & $\mathrm{I} 2$ & 0.1749 & 0.2002 & -0.0253 \\
\hline 5 & 14 & 0.0250 & 0.4504 & -0.4254 \\
\hline
\end{tabular}

Based on the results of the sensitivity analysis of the weights of the criteria used in the ranking of safety climate in different industrial sectors in project-oriented organizations, it is observed that a change in the ranking order would occur if the GQ1 (Safety and Competence Awareness), GQ2 (Occupational Safety Management commitment), GQ4 (Safety practices and procedures) and GQ5 (Organizational environment) change their values beyond the limits shown in Table 4. On the other hand, even if the value of the GQ3 (Safety training and tools) criterion weights vary within very extreme limits, it would not cause changes in the ranking of alternatives. 
4.2 Multi-criteria analysis of occupational safety climate in project-oriented organizations in different industrial sectors

In the continuation of the research, a multi-criteria analysis and final ranking of occupational climate safety levels in project-oriented organizations in different industrial sectors were performed. The baseline data for the implementation of the PROMETHEE method represent the average estimations of the respondents for all five questionnaire groups in the three positions (manager, production worker and non-production worker) in all five industry sectors studied (Table 5).

Table 5: PROMETHEE calculation baseline data (occupational safety climate in different industrial sectors)

\begin{tabular}{|l|c|c|c|c|c|}
\hline \multirow{2}{*}{ Alternatives } & \multicolumn{2}{|c|}{ Criteria } & \multicolumn{3}{c|}{} \\
\cline { 2 - 5 } & GQ1 & GQ2 & GQ3 & GQ4 & GQ5 \\
\hline I1 WP1 & 3.69 & 4.17 & 3.96 & 3.68 & 2.87 \\
\hline I1 WP2 & 4.46 & 3.23 & 3.51 & 3.79 & 3.05 \\
\hline I1 WP3 & 4.10 & 3.53 & 4.03 & 3.69 & 3.60 \\
\hline I2 WP1 & 4.47 & 3.48 & 3.65 & 3.21 & 3.02 \\
\hline I2 WP2 & 4.38 & 3.13 & 3.26 & 3.11 & 2.76 \\
\hline I2 WP3 & 4.13 & 3.17 & 4.08 & 2.79 & 4.00 \\
\hline I3 WP1 & 4.50 & 4.05 & 3.71 & 3.94 & 2.42 \\
\hline I3 WP2 & 4.18 & 3.54 & 3.79 & 3.69 & 2.89 \\
\hline I3 WP3 & 4.62 & 3.08 & 3.58 & 3.50 & 4.16 \\
\hline I4 WP1 & 4.50 & 2.25 & 2.50 & 2.36 & 4.00 \\
\hline I4 WP2 & 4.43 & 2.59 & 3.02 & 2.94 & 3.06 \\
\hline I4 WP3 & 4.25 & 3.00 & 1.67 & 2.00 & 3.00 \\
\hline I5 WP1 & 4.75 & 5.00 & 3.83 & 4.86 & 2.50 \\
\hline I5 WP2 & 4.04 & 3.35 & 3.41 & 3.51 & 3.10 \\
\hline I5 WP3 & 4.25 & 3.17 & 4.17 & 4.00 & 4.00 \\
\hline
\end{tabular}

After determining the input data, the predefined function of preference and weight coefficients of criteria, an evaluation matrix was formed, on the basis of which the ranking of alternatives was made.

The results of the complete ranking (PROMETHEE II) of safety climate in project-oriented organizations based on the opinions of employees at different workplaces in different industrial sectors, as well as the flows of preferences, are shown in Table 6. Additionally, the ranking results are also shown using the GAIA plane (Figure 2).

Table 6: Results of a complete ranking of safety climate in project-oriented organizations based on the opinions of employees at different workplaces in different industrial sectors

\begin{tabular}{|l|l|l|l|l|}
\hline Rank & Alternatives & $\boldsymbol{\Phi}$ & $\boldsymbol{\Phi}-$ & $\boldsymbol{\Phi}$ \\
\hline 1 & I5 WP1 & 0.6502 & 0.0214 & 0.6288 \\
\hline 2 & I3 WP1 & 0.4572 & 0.0500 & 0.4072 \\
\hline 3 & I1 WP1 & 0.3574 & 0.1570 & 0.2003 \\
\hline 4 & I3 WP2 & 0.2930 & 0.1428 & 0.1501 \\
\hline 5 & I1 WP3 & 0.2930 & 0.1999 & 0.0932 \\
\hline 6 & I2 WP1 & 0.2500 & 0.1572 & 0.0928 \\
\hline 7 & I1 WP2 & 0.2215 & 0.1572 & 0.0643 \\
\hline 8 & I5 WP3 & 0.2644 & 0.2071 & 0.0574 \\
\hline 9 & I2 WP2 & 0.2285 & 0.2359 & -0.0074 \\
\hline 10 & I5 WP2 & 0.1930 & 0.2571 & -0.0642 \\
\hline 11 & I3 WP3 & 0.1786 & 0.2857 & -0.1072 \\
\hline 12 & I2 WP3 & 0.1572 & 0.3572 & -0.2000 \\
\hline 13 & I4 WP2 & 0.1285 & 0.3931 & -0.2646 \\
\hline 14 & I4 WP3 & 0.0714 & 0.5432 & -0.4718 \\
\hline 15 & I4 WP1 & 0.0714 & 0.6504 & -0.5790 \\
\hline
\end{tabular}


Based on the obtained results, it is observed that the highest-ranked alternatives are I5 WP1, I3 WP1 and I1 WP1, respectively. This result is expected, as managers have best evaluated safety climate in their workplaces. In addition, safety climate is also rated very favorably in complete industries in which these managers are engaged. When it comes to production workers on projects, the most favorable safety climate is in energy workplaces (I3 WP2). For non-productive workers, the most favorable safety climate is on projects in the field of mechanical engineering. On the other hand, the most unfavorable safety climate was found in all jobs in construction projects (I4 WP2, I4 WP3, 14 WP1, respectively). These are workplaces where almost all safety climate factors are needed. It seems very worrying that the absolute most unfavorable safety climate has been found among managers on building projects. This fact can be the cause and explanation for the generally unfavorable safety climate in these types of projects and ultimately very unfavorable occupational safety level of employees.

The GAIA plane positions of alternatives are such that those with similar profiles relative to the criteria are positioned closer to each other. Finally, looking at the positions of the alternative in relation to the positions of the criteria, in Figure 2, all the workplaces and safety climate factors that have been poorly evaluated can be observed, which is a starting point for the more detailed analyses.

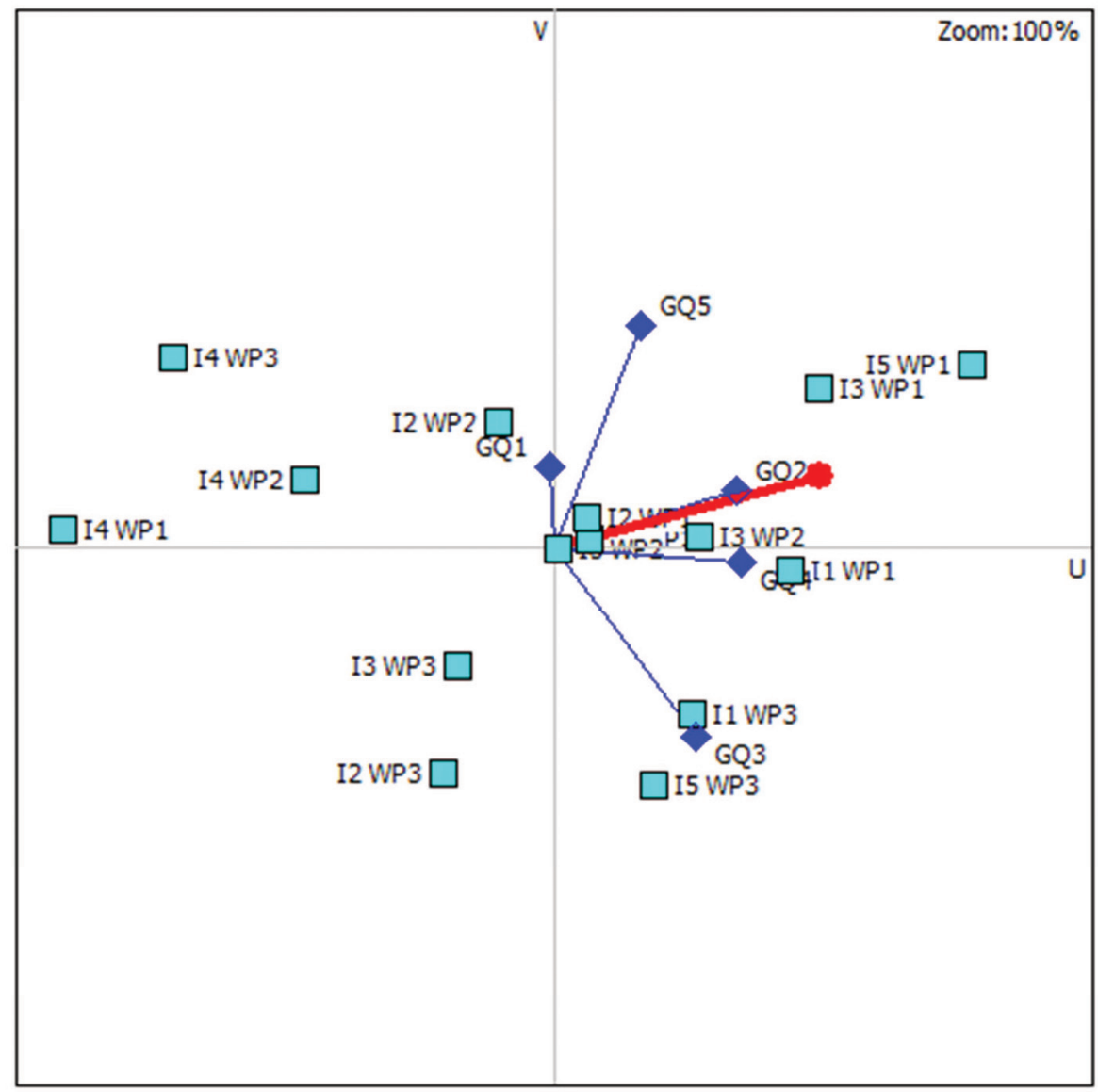

Figure 2: GAIA plane of the ranking of safety climate at different workplaces in different industrial sectors

In order to determine the magnitude of the preferred relationships with a given ranking of occupational safety climate in project-oriented organizations in different industrial sectors, a sensitivity analysis of the criterion weights of the criteria was performed (Table 7). 
Table 7: Weight coefficient stability intervals

\begin{tabular}{|l|l|l|l|}
\hline \multirow{2}{*}{ Criteria } & Starting weight & \multicolumn{2}{|l|}{ Stability intervals (\%) } \\
\cline { 3 - 4 } & coefficients (\%) & $\min$ & $\max$ \\
\hline GQ1 & 19.970 & 17.70 & 20.03 \\
\hline GQ2 & 20.032 & 19.26 & 33.29 \\
\hline GQ3 & 20.002 & 19.93 & 20.96 \\
\hline GQ4 & 20.021 & 19.95 & 22.52 \\
\hline GQ5 & 19.972 & 18.85 & 20.05 \\
\hline
\end{tabular}

Based on the results of the sensitivity analysis of weight coefficients of the criteria used in the ranking of occupational safety climate in project-oriented organizations in different industrial sectors, very narrow stability intervals are observed indicating that changing the ranking order of alternatives would occur with very small changes in the weight coefficients.

\section{Conslusion}

Safety climate as the basis for the formation of adequate occupational safety in an organization is a very important area of research. This area becomes even more significant when studying occupational safety in project-oriented organizations, that is, projects as temporary structures. In order to analyze the influential factors of safety climate in detail, multi-criteria analysis methods represent very useful tools. The multi-criteria analysis of safety climate in project-oriented organizations, i.e. on the implementation of various industrial projects leads to some significant conclusions. Through the analysis of the sample industrial sectors with significant safety climate deficiencies were identified. In that sense, it is necessary to emphasize high-rise construction as an industrial sector in which safety climate shows serious shortcomings. In addition, the methodology applied allowed for a precise determination of factors whose enhancement would significantly improve safety climate in project-oriented organizations, both at the level of individual jobs and in the organization as a whole. At the industrial sector level, Occupational Safety, Management commitment and Organizational environment turned out to be the factors that, in terms of improving safety climate, require significant improvements. The analysis of individual jobs indicates that with a more appropriate Occupational Safety Management commitment, safety climate would be improved in most of the jobs studied. Adopting these guidelines would, in practice, improve safety climate in project-oriented organizations as well as occupational safety, which would, of course, reduce the number of workplace injuries as one of the imperatives of modern business.

Finally, with the presented methodology, it is possible to assess safety climate in any project-based organization and, in case of shortcomings, focus managers' attention on safety climate factors that need to be improved.

\section{REFERENCES}

[1] Alruqi, W.M., Hallowell, M.R., \& Techera, U. (2018). Safety climate dimensions and their relationship to construction safety performance: A meta-analytic review. Safety Science, 109, 165-173. DOI: 10.1016/j.ssci.2018.05.019

[2] Anand, G., \& Kodali, R. (2008). Selection of lean manufacturing systems using the PROMETHEE. Journal of Modelling in Management, 3(1), 40-70. DOI: 10.1108/17465660810860372

[3] Bamel, U.K., Pandey, R., \& Gupta, A. (2020). Safety climate: Systematic literature network analysis of 38 years (1980-2018) of research. Accident Analysis and Prevention, 135, 105387. DOI: 10.1016/j.aap.2019.105387

[4] Brans, J., \& De Smet, Y. (2016). PROMETHEE Methods. In S. Greco, M. Ehrgott, \& J. Figueira, Multiple Criteria Decision Analysis. International Series in Operations Research \& Management Science, 233, 163-195, New York, NY: Springer.

[5] Brans, J.P., \& Mareschal, B. (1994). The PROMCALC and GAIA decision support system for multicriteria decision aid. Decision Support Systems, 12, 297-310. DOI: 10.1016/0167-9236(94)90048-5

[6] Brans, J.P., Vincke, P.H., \& Mareschal, B. (1986). How to select and how to rank projects: The Promethee method. European Journal of Operational Research, 24(2), 228-238. DOI: 10.1016/03772217(86)90044-5

[7] Chen, Y., McCabe, B., \& Hyatt, D. (2018a). A resilience safety climate model predicting construction safety performance. Safety Science, 109, 434-445. DOI: 10.1016/j.ssci.2018.07.003 
[8] Chen, Y.-L., Liu, K.-H., \& Chang, C.-C. (2018b). Practical application of safety climate: A case study in the Taiwanese steel industry. International Journal of Industrial Ergonomics, 67, 67-72. DOI: 10.1016/j.ergon.2018.04.010

[9] Chirag, Singh, M., \& Goel, V.K. (2016). Entropy-PROMETHEE based decision making methodology for selection of brake friction material. International Journal of Technical Research, 5 (2), 224-228. ISSN 2278-5787

[10] Curcuruto, M., Griffin, M.A., Kandola, R., \& Morgan, J.I. (2018). Multilevel safety climate in the UK rail industry: A cross validation of the Zohar and Luria MSC scale. Safety Science, 110, 183-194. DOI: 10.1016/j.ssci.2018.02.008

[11] Flatau-Harrisona, H., Griffin, M.A., \& Gagne, M. (2020). Trickling down: The impact of leaders on individual role clarity through safety climate strength across time. Safety Science, 121, 485-495. DOI: 10.1016/j.ssci.2019.09.009

[12] Hafezalkotob, A., \& Hafezalkotob, A. (2016). Extended MULTIMOORA method based on Shannon entropy weight for materials selection. Journal of Industrial Engineering International, 12, 1-13. DOI: 10.1007/s40092-015-0123-9

[13] He, Q., Dong, S., Rose, T., Li, H., Yin, Q., \& Cao, D. (2016). Systematic impact of institutional pressures on safety climate in the construction industry. Accident Analysis and Prevention, 93, 230-239. DOI: 10.1016/j.aap.2015.11.034

[14] Hsu, S.H., Lee, C.C., Wu, M.C., \& Takano, K. (2008). A cross-cultural study of organizational factors on safety: Japanese vs. Taiwanese oil refinery plants. Accident Analysis and Prevention 40, 24-34. DOI: 10.1016/j.aap.2007.03.020.

[15] Huang, Y-H., Verma, S.K., Chang, W.-R., Courtney, T.K., Lombardi, D.A., Brennan, M.J., \& Perry, M.J. (2012). Management commitment to safety vs. employee perceived safety training and association with future injury. Accident Analysis and Prevention, 47, 94- 101. DOI: 10.1016/j.aap.2011.12.001

[16] Ishizaka, A., \& Resce, G. (2020). Best-Worst PROMETHEE method for evaluating school performance in the OECD's PISA project. Socio-Economic Planning Sciences, in press, DOI: 10.1016/j.seps.2020.100799

[17] Jiang, L., Yu, G., Li, Y., \& Li, F. (2010). Perceived colleagues' safety knowledge/behavior and safety performance: Safety climate as a moderator in a multilevel study. Accident Analysis and Prevention, 42, 1468-1476. DOI:10.1016/j.aap.2009.08.017

[18] Jiang, L., Lavaysse, L.M., \& Probst, T.M., (2018). Safety climate and safety outcomes: a metaanalytic comparison of universal vs. Industry-specific safety climate predictive validity. Work \& Stress, 33 (1), 4157. DOI: 10.1080/02678373.2018.1457737

[19] Kasim, H., Che Hassan, C.R., Hamid, M.D., Emami, S.D., \& Danaee, M. (2019). The relationship of safety climate factors, decision making attitude, risk control, and risk estimate in Malaysian radiation facilities. Safety Science, 113, 180-191. DOI: 10.1016/j.ssci.2018.11.025

[20] Khodeir, L.M., \& Nabawy, M. (2019). Identifying key risks in infrastructure projects - Case study of Cairo Festival City project in Egypt. Ain Shams Engineering Journal, 10, 613-621. DOI: 10.1016/j.asej.2018.11.003

[21] Kilic, H., Zaim, S., \& Delen, D. (2015). Selecting "The Best”' ERP system for SMEs using a combination of ANP and PROMETHEE methods. Expert Systems with Applications,42 (5) , 2343-2352. DOI:10.1016/j.eswa.2014.10.034

[22] Kim, N.K., Abdul Rahim, N.F., Iranmanesh, M., \& Foroughi, B. (2019). The role of the safety climate in the successful implementation of safety management systems. Safety Science, 118, 48-56. DOI: 10.1016/j.ssci.2019.05.008

[23] Li, J., Zhang, J., \& Suo, W. (2019). Risk assessment in cross-border transport infrastructure projects: A fuzzy hybrid method considering dual interdependent effects. Information Sciences, 488, 140-157. DOI: 10.1016/j.ins.2019.03.028

[24] Lin, S.H., Tang, W.J., Miao, J.Y., Wang, Y.M., \& Wang, P.X. (2008). Safety climate measurement at workplace in China: A validity and reliability assessment. Safety Science, 46, 1037-1046. DOI: 10.1016/j.ssci.2007.05.001

[25] Lingard, H., Hallowell, M., Salas, R., \& Pirzadeh, P. (2017). Leading or lagging? Temporal analysis of safety indicators on a large infrastructure construction project. Safety Science, 91, 206-220. DOI: 10.1016/j.ssci.2016.08.020

[26] Mareschal, B., \& Brans, J. (1988). Geometrical representations for MCDA. European Journal of Operational Research, 34 (1), 69-77. DOI: 10.1016/0377-2217(88)90456-0

[27] Marin, L.S., Lipscomb, H., Cifuentes, M., \& Punnett, L. (2019). Perceptions of safety climate across construction personnel: Associations with injury rates. Safety Science, 118, 487-496. DOI: 10.1016/j.ssci.2019.05.056

[28] Milijic, N., Mihajlovic, I., Nikolic, D. \& Zivkovic, Z. (2014). Multicriteria analysis of safety climate measurements at workplaces in production industries in Serbia. International Journal of Industrial Ergonomics, 44, 510-519. DOI: 10.1016/j.ergon.2014.03.004 
[29] Milijic, N., Mihajlovic, I., Strbac, N., \& Zivkovic, Z. (2013). Developing a Questionnaire for Measuring Safety Climate in the Workplace in Serbia. International Journal of Occupational Safety and Ergonomics, 19(4), 631-645. DOI: 10.1080/10803548.2013.11077020

[30] Murat, S., Kazan, H., \& Coskun, S. (2015). An Application for Measuring Performance Quality of Schools by Using the PROMETHEE Multi-Criteria Decision Making Method. Procedia - Social and Behavioral Sciences 195 , 729 - 738. DOI: 10.1016/j.sbspro.2015.06.344

[31] Newaz, M.T., Davis, P., Jefferies, M., \& Pillay, M. (2019). The psychological contract: A missing link between safety climate and safety behaviour on construction sites. Safety Science, 112, 9-17. DOI: 10.1016/j.ssci.2018.10.002

[32] Nikolic, Dj., Jovanovic, I., Mihajlovic, I., \& Zivkovic, Z. (2009). Multi-criteria ranking of copper concentrates according to their quality - An element of environmental management in the vicinity of copper - Smelting complex in Bor, Serbia. Journal of Environmental Management, 91, 509-515. DOI: 10.1016/j.jenvman.2009.09.019

[33] Pandit, B., Alberta, A., Patil, Y., \& Al-Bayati, A.J. (2019). Impact of safety climate on hazard recognition and safety risk perception. Safety Science, 113, 44-53. DOI: 10.1016/j.ssci.2018.11.020

[34] Probst, T.M., Goldenhar, L.M., Byrd, J.L., \& Betit, E. (2019). The Safety Climate Assessment Tool (SCAT): A rubric-based approach to measuring construction safety climate. Journal of Safety Research, 69, 43-51. DOI: 10.1016/j.jsr.2019.02.004

[35] Puska, A., Beganovic, A., \& Sadic, S. (2018). Model for investment decision making by applying the multi-criteria analysis method. Serbian Journal of Management, 13(1), 7-28. DOI: 10.5937/sjm13-12436

[36] Saunders, L.W., Kleiner, B.M., McCoy, A.P., Ellis, K.P., Smith-Jackson, T., \& Wernz, C. (2017). Developing an inter-organizational safety climate instrument for the construction industry. Safety Science, 98, 1724. DOI: 10.1016/j.ssci.2017.04.003

[37] Sennaroglu, B., \& Celebi, G.V. (2018). A military airport location selection by AHP integrated PROMETHEE and VIKOR methods. Transportation Research Part D: Transport and Environment, 59, 160-173. DOI: 10.1016/j.trd.2017.12.022

[38] Sheehan, C., Donohue, R., Shea, T., Cooper, B., \& De Cieri, H. (2016). Leading and lagging indicators of occupational health and safety: Themoderating role of safety leadership. Accident Analysis and Prevention, 92, 130-138. DOI: 10.1016/j.aap.2016.03.018

[39] Stackhouse, M., \& Turner, N. (2019). How do organizational practices relate to perceived system safety effectiveness? Perceptions of safety climate and co-worker commitment to safety as workplace safety signals. Journal of Safety Research, 70, 59-69. DOI: 10.1016/j.jsr.2019.04.002

[40] Stiles, S., Ryan, B., \& Golightly, D. (2018). Evaluating attitudes to safety leadership within rail construction projects. Safety Science, 110, 134-144. DOI: 10.1016/j.ssci.2017.12.030

[41] Turnberg, W., \& Daniell, W. (2008). Evaluation of a healthcare safety climate measurement tool. Journal of Safety Research, 39, 563-568. DOI:10.1016/j.jsr.2008.09.004

[42] Versteeg, K., Bigelow, P., Dale, A.M., \& Chaurasia, A. (2019). Utilizing construction safety leading and lagging indicators to measure project safety performance: A case study. Safety Science, 120, 411-421. DOI: 10.1016/j.ssci.2019.06.035

[43] Winge, S., Albrechtsen, E., \& Arnesen, J. (2019). A comparative analysis of safety management and safety performance in twelve construction projects. Journal of Safety Research, 71, 139-152. DOI: 10.1016/j.jsr.2019.09.015

[44] Xia, N., Xie, Q., Hu, X., Wang, X., \& Meng, H. (2020). A dual perspective on risk perception and its effect on safety behavior: A moderated mediation model of safety motivation, and supervisor's and coworkers' safety climate. Accident Analysis and Prevention, 134, 105350. DOI: 10.1016/j.aap.2019.105350

[45] Yang, H., Chew, D.A.S., Wu, W., Zhou, Z., \& Li, Q. (2012). Design and implementation of an identification system in construction site safety for proactive accident prevention. Accident Analysis \& Prevention, 48, 193-203. DOI: 10.1016/j.aap.2011.06.017.

[46] Zaira, M.M, \& Hadikusumo, B.H.W. (2017). Structural equation model of integrated safety intervention practices affecting the safety behaviour of workers in the construction industry. Safety Science, 98, 124135. DOI: 10.1016/j.ssci.2017.06.007

[47] Zohar, D. (1980). Safety climate in industrial organizations: theoretical and applied implications. Journal of Applied Psychology, 60(1), 96-102. DOI: 10.1037/0021-9010.65.1.96

[48] Zivkovic, Z., Arsic, M., \& Nikolic. Dj. (2017). The University of Belgrade on ARWU List - PART I: The Impact of Individual Faculties on the Achieved Position Using PROMETHEE-GAIA Method, Serbian Journal of Management, 12(2), 171 - 187. DOI: 10.5937/sjm12-13562

Received: 2020-03-02

Revisions requested: 2020-05-08

Revised: 2020-07-01 (1 revision)

Accepted: 2020-07-26 


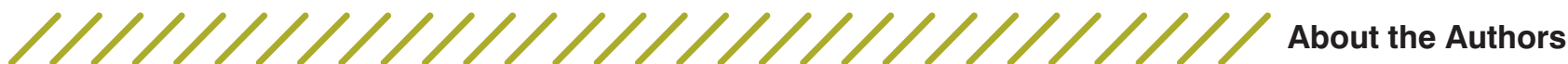

\author{
Nenad Milijić \\ University of Belgrade, Technical Faculty in Bor, Serbia \\ nmilijic@tfbor.bg.ac.rs
}

Nenad Milijić, PhD, is an assistant professor at the University of Belgrade, Technical Faculty in Bor, Engineering Management Department. His main research interests include manufacturing management, occupational safety, project management and application of quantitative methods in management. He is the author or co-author of two books, three chapters in monographs, and over 80 papers published in scientific journals and at scientific conferences.

\section{Anđelka Stojanović \\ University of Belgrade, Technical Faculty in Bor, Serbia anstojanovic@ttbor.bg.ac.rs}

Anđelka Stojanović, MSc, is a teaching assistant at the University of Belgrade, Technical Faculty in Bor, Engineering Management Department. She graduated and completed her master studies at the Technical Faculty in Bor, University of

Belgrade. Currently, she is a PhD student at the same university. She teaches the following courses: Decision Making Theory, Reliability Theory, Logistics, and Theoretical Fundamentals of the Master Work Preparation. The areas of her research interest and competence are multi-criteria decision-making methods, statistical analysis, corporate social responsibility, and sustainable development.

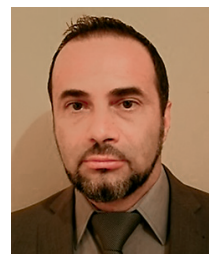

Ivan Mihajlović University of Belgrade, Technical Faculty in Bor, Serbia imihajlovic@tfbor.bg.ac.rs

Ivan Mihajlović, PhD, is a full professor at the University of Belgrade, Technical Faculty in Bor, Engineering Management Department. He teaches the following courses:

Production Management, System Theory, Logistics and Operational Management. Currently, the main focus is on exploring and solving problems related to operational management with the application of methods of linear and nonlinear statistical analysis,

kinetic analysis of technological processes and ecological management. He is the author or co-author of four books, five chapters in monographs, and over 120 papers published in international and national scientific journals.

Ivan Jovanović
University of Belgrade, Technical Faculty in Bor, Serbia
ijovanovic@tfbor.bg.ac.rs

Ivan Jovanović, $\mathrm{PhD}$, is a full professor at the University of Belgrade, Technical Faculty in Bor, Engineering Management Department. He teaches the following courses: Entrepreneurship, Reliability Theory, Operational Research 2, Knowledge Management. $\mathrm{He}$ is the author or co-author of 7 books, four chapters in monographs, and over 100 papers published in scientific journals and at scientific conferences.

\section{Momir Popović \\ University of Belgrade, Technical Faculty in Bor, Serbia mpopovic@tfbor.bg.ac.rs}

Momir Popović, MSc, is a teaching assistant at the University of Belgrade, Technical Faculty in Bor, Engineering Management Department. He has completed his undergraduate and master academic studies at the same University. Currently, he is a

$\mathrm{PhD}$ student at Technical Faculty in Bor, University of Belgrade. He is a teaching assistant at the following courses: Project Management, Decision Theory, Production Management, Reliability Theory and Management Information Systems.
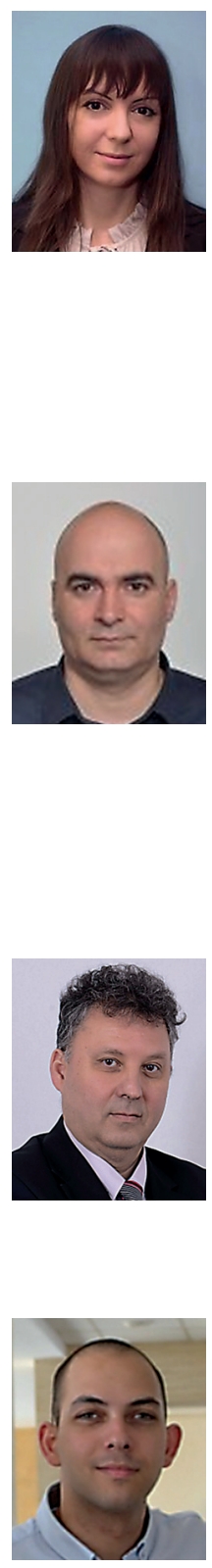